\title{
ORGANIZAÇÕES COLABORATIVAS COMO SISTEMAS ABERTOS: CONTRIBUIÇÕES DO METAPROJETO PARA FOMENTAR AÇÕES DE INOVAÇÃO SOCIAL
}

\author{
Coral Michelin Basso (UNISINOS); Gustavo Severo de Borba, Dr. \\ (UNISINOS); Karine Freire, Dra. (UNISINOS); Carlo Franzato, Dr. (UNISINOS)
}

\begin{abstract}
RESUMO
No contexto em que tudo que se ouve é crise, urgência e mudança, falar sobre as possibilidades de ação em prol de um futuro sustentável é uma necessidade. Estão surgindo, em diversos lugares no mundo, iniciativas com capacidade de propor uma visão de bem-estar renovada, calcada na sustentabilidade e no agir coletivo, conhecidas como organizações colaborativas. Tais empreendimentos promovem pequenas rupturas locais no modelo econômico vigente, ao mesmo tempo que criam casos promissores de inovação social. Ao observar as características das organizações colaborativas e as relações que estabelecem com o ecossistema onde estão inseridas, o presente estudo estabelece uma conexão comparativa entre essas organizações e os sistemas abertos, apresentando um conceito que amplia o entendimento acerca do funcionamento e das possibilidades de ação das organizações. O objetivo, com isso, é apontar as possibilidades do design - encarado aqui sob seu viés estratégico - em fomentar as atividades de inovação social das organizações colaborativas. Utilizando o framework conceitual do metadesign, são sugeridas duas contribuições para dar suporte à organização; para habilitar seus atores a serem co-criadores; e também para transformar o próprio designer, que se assume então o papel de articulador desse sistema complexo: o co-design e o seeding.
\end{abstract}

\section{ABSTRACT}

In a context where all you can hear is crisis, urgency and change, to speak about the possibilities of action towards a sustainable future is a necessity. Initiatives are emerging in several places around the world, that are able to propose a renewed vision of well being based on sustainability and collective action, known as collaborative organizations. Such projects promote small local ruptures on the current economic model, while creating promising cases of social innovation. By observing the characteristics of these collaborative organizations and the relations they establish with the ecosystem where they are inserted, the present study establishes a comparative connection between these organizations and open systems, presenting a concept that amplifies the understanding of the operation and possibilities of action of such organizations. With this, the goal is to point the possibilities of design - understood here under its strategic scope - to foster the actions of social innovation of these collaborative organizations. Using the conceptual framework of metadesign, two contributions are suggested to support the organization; to enable its actors to be co-creators; and to transform the designer himself, who then assumes the role of articulator of this complex system: co-design and seeding. 


\section{INTRODUÇÃO}

Estamos em uma era de contrastes e extremos, na qual luxo e miséria, abundância e escassez, individual e coletivo, convivem lado a lado. O modelo econômico vigente entra em confronto direto com a urgência dos problemas ambientais que ele próprio causa. O último relatório do Painel Intergovernamental de Mudanças Climáticas (2014) deixa essa urgência bastante clara: o tempo de agir é agora, e a melhor forma de ação é coletiva. Nesse contexto, falar sobre as possibilidades do agir coletivo em prol de um futuro sustentável é uma necessidade.

A definição de sustentabilidade (ou de desenvolvimento sustentável, como é também usado) deixa clara a noção de interdependência entre esferas da vida, seres e sistemas. Pontes e Bezerra (2003, p.6), após traçar a evolução do conceito, o descreveram da seguinte forma: "Descobrir e utilizar uma nova consciência que nos permita progredir em todas as dimensões ecológicas (humana, social, econômica e ambiental), apoiando, conservando e restaurando todos os recursos que o planeta coloca à nossa disposição para as futuras gerações". Portanto, é impossível abordar a sustentabilidade sem assumir uma visão ecossistêmica da realidade.

Ecossistema é um termo da ecologia, que designa o sistema estável, equilibrado e autossuficiente, composto por biocenose (conjunto de seres vivos) e biótipo (elementos necessários para os seres vivos realizarem suas atividades) (BRAGA et al, 2002). Essa noção de ecossistema pode ser emprestada a outros campos do conhecimento e explorada sob, por exemplo, um ângulo mais social, humano, caracterizando um conjunto de recursos socioeconômicos e culturais, além dos naturais. $O$ presente estudo foca sua atenção no ecossistema humano, entendido como "o conjunto de sistemas biofísicos e sociais em interação, capazes de adaptação e sustentabilidade ao longo do tempo" (FRANZATO et al, 2015, p.168), por entender que é principalmente nele que surgem os maiores desafios enfrentados no presente e, ao mesmo tempo, as maiores possibilidades de atuação por parte dos designers. É também na esfera social que reside a inovação.

$\mathrm{Na}$ trajetória histórica da construção do macro-sistema social, econômico e tecnológico vigente e até hoje em dia, os designers foram vistos como parte constituinte do problema socioambiental, por projetarem e promoverem uma noção de bem-estar incompatível com a resiliência do planeta. Porém, mais recentemente, os designers têm se esforçado para mudar essa imagem, atuando como agentes na transição para estilos de vida mais sustentá- veis. Com uma visão positiva, John Thackara (2008) menciona diversas iniciativas que estão propondo, explorando e testando soluções e modelos alternativos para os problemas que enfrentamos - muitas delas relacionadas ao design, ou articuladas por designers. Uma das iniciativas mais promissoras que podemos ver surgindo em diversas partes do mundo são aquilo que Meroni (2007), Manzini e Jégou (2008) chamam de organizações colaborativas. São comunidades estabelecidas, compostas de pessoas criativas, que atuam em escala local e, rearticulando os recursos já existentes aos quais têm acesso, propõem inovações sociais. Ao agirem por conta própria para resolverem os próprios desafios, essas comunidades desenvolvem relações de confiança pessoa-a-pessoa, enquanto fortalecem o tecido social de suas localidades e inspiram uma nova visão de bem-estar, mais sustentável, nos seus pares. Essas comunidades desempenham um papel importante na lenta transição do macro-sistema insustentável atual, para um que repense as instâncias de produção e consumo, e leve em consideração os requisitos para o desenvolvimento sustentável. Por conta desse potencial de ruptura e inovação é que estabelecemos as organizações colaborativas como nosso objeto de estudo.

Quando deslocamos o campo de visão para observar essas organizações à distância, em meio às relações que estabelecem no ecossistema onde estão inseridas, podemos perceber que elas assumem certas características dos sistemas abertos do metaprojeto (metadesign) e de Edgar Morin. Veremos que elas passam a ser entendidas como entidades complexas cujo todo tem mais significado que o somatório de suas partes; como altamente correlatas ao contexto; como organismos que realizam trocas dinâmicas com o meio, assim mantendo seu equilíbrio interior. Enquanto regulam sua autonomia pela abertura, as organizações colaborativas estão também promovendo o equilíbrio do próprio ecossistema. Tal comparação - das organizações colaborativas com os sistemas abertos - traz à superfície uma nova visão acerca do funcionamento e das possibilidades de ação dessas organizações.

A relevância de aprofundar o conhecimento sobre os mecanismos de funcionamento das organizações colaborativas está em poder cultivar suas ações inovadoras de transformação social. Assim sendo, o objetivo desse artigo é apontar as possibilidades do designer em fomentar as atividades das organizações colaborativas, usando o framework conceitual do metadesign para dar suporte à organização; para habilitar seus atores no papel de co-designers; e também para transformar o próprio designer, que 
assume o papel de articulador de um sistema complexo. Esperando cumprir esse propósito, iremos, primeiro, caracterizar os sistemas abertos à luz de Morin (2005) e de Fischer e Giaccardi (2004, 2005), e também as organizações colaborativas a partir dos estudos de Manzini (2007, 2008, 2010), principalmente. Em seguida vamos comparar as organizações colaborativas e os sistemas abertos, para finalmente entender de que forma o metaprojeto contribui na concepção, na evolução e na replicação das organizações. Dois caminhos são apontados como resultado, o do co-design e o da semente (seeding).

\section{SISTEMAS ABERTOS}

“Em qualquer sistema natural, matéria e energia são conservadas" (BRAGA et al, 2002, p.7). Para podermos entender o conceito de sistema aberto aos olhos do design, primeiro precisamos rever a sua origem, na física. A lei da conservação da massa e a primeira lei da termodinâmica são semelhantes: elas dizem que, em um sistema, a matéria ou a energia, respectivamente, não podem ser criadas ou destruídas, apenas transformadas. Já a segunda lei da termodinâmica estabelece que todo processo de transformação de energia ocorre mediante a perda da sua qualidade, ou seja, a energia é dispersa para o ambiente, enquanto é usada. Um aspecto importante dessa segunda lei estabelece que todo corpo, ou todo sistema, que tem uma forma ordenada precisa de energia de alta qualidade para manter seu nível de entropia baixo. Os sistemas têm como característica fundamental a busca pelo estado de equilíbrio dinâmico, este ocorrendo por meio da ação dos mecanismos internos que regulam as trocas com o meio ambiente e adaptam constantemente a estrutura às mudanças, tanto internas quanto externas. Como a tendência de todo sistema é perder energia para o ambiente, a manutenção desse equilíbrio ocorre por meio do fornecimento contínuo de energia e, no caso dos sistemas sociais, também de informação ou matéria.

Morin (2005) explica que os sistemas abertos têm origem nessas leis da termodinâmica, caracterizados pela dependência de alimentação externa, ou seja, são ditos abertos pois realizam trocas com o meio exterior onde estão inseridos, sendo que alguns desses sistemas fazem trocas não só materiais e energéticas, mas organizacionais e informacionais também. Para atingir seu equilíbrio interno, o sistema aberto depende dessas trocas com o ambiente. Dito de outra forma, a integridade do seu interior depende do exterior. Isso significa que, se por um lado "o sistema deve se fechar ao mundo exterior a fim de manter suas estruturas e seu meio interior", por outro é justamente "sua abertura que permite esse fechamento" (MORIN, 2005, p.21). Vale atentar para o fato de que o entendimento do funcionamento do sistema aberto não se dá apenas na observação do sistema em si, mas também na observação das relações que ele estabelece com o seu meio ambiente, seu macro-sistema.

Os sistemas abertos do metaprojeto. Segundo Fischer e Giaccardi (2005), sistemas que sustentam a criatividade e a evolução precisam ser sistemas abertos, para oportunizar a adaptação dos mesmos a novas realidades e novos desafios, dado que nem todos os problemas e variáveis podem ser antecipados e decididos no momento de projetá-los. Portanto, enquanto sistemas fechados não realizam trocas e, portanto, são incapazes de lidar com as mudanças do ambiente que os engloba, os sistemas abertos, por sua vez, são mais maleáveis e conseguem resolver problemas emergentes, dentro do seu contexto colaborativo (GIACCARDI, 2003). Embora os autores tratem, majoritariamente, de sistemas tecnológicos, os conceitos que abordam podem facilmente ser transpostos para o contexto de sistemas sociais, uma vez que lidam com criatividade social, resolução de problemas e usuários como co-designers de soluções.

Desenvolvendo mais o conceito, Fischer e Giaccardi (2005) apresentam quatro princípios dos sistemas abertos: (1) os sistemas devem evoluir para lidar com contextos que mudam com o tempo e com variáveis imprevistas, não podendo ser completamente projetados antes do seu uso; (2) o sistema deve evoluir na mão dos seus usuários, dando aos stakeholders (atores interessados na resolução do problema) a habilidade de modificar o sistema; (3) sistemas devem ser projetados, desde o princípio, para a evolução; (4) a evolução do sistema deve acontecer de forma distribuída, no tempo, no espaço e entre os atores. De acordo com Manzini (2008), o adjetivo "distribuído" do último ponto, indica a existência de uma arquitetura horizontal de sistema onde um número relevante e interconectado de atores (ou artefatos tecnológicos) desempenham atividades complexas. Ou seja, indica a existência de uma rede entre atores locais ou entre mais de uma localidade -, algo significativo para entendermos as características das organizações colaborativas. 


\section{ORGANIZAÇÕES COLABORATIVAS}

Em 1989, Felix Guattari propôs um conceito para o que chamou de ecosofia (entendido aqui como sustentabilidade), baseado em três registros ecológicos: o do meio ambiente, o da subjetividade humana e o das relações sociais. Justamente na intersecção desses três registros que se situa o design estratégico para a sustentabilidade referido por Ezio Manzini - uma atividade que objetiva fomentar a inovação radical orientada para a sustentabilidade, reduzindo drasticamente a utilização de recursos ambientais, reforçando o tecido social e regenerando a qualidade dos contextos de vida (MANZINI, 2008; MANZINI, VEZZOLI, 2011). Manzini afirma que a sustentabilidade vai ocorrer por meio de uma descontinuidade no macro-sistema sociotécnico, atingindo suas dimensões física, econômica, ética, estética e cultural. Essa mudança será provavelmente alavancada por pequenas rupturas locais, promovidas por uma multiplicidade de atores sociais capazes de agir fora do modelo econômico dominante. Essas iniciativas locais já existem: elas rompem com a maneira tradicional de fazer as coisas; constroem uma nova visão de mundo, novas oportunidades e soluções para os problemas existentes; promovem a aprendizagem e reforçam as conexões sociais (JÉGOU, MANZINI, 2008; MANZINI, 2008; MANZINI, 2010). Um exemplo dessas iniciativas são as comunidades criativas - grupos de pessoas que inventam, aprimoram e gerenciam soluções inovadoras -, que conseguem convergir interesses pessoais, sociais e ambientais em suas propostas.

\section{De comunidades criativas a organizações cola-}

borativas. De acordo com Meroni (2007), todas comunidades criativas compartilham características em comum: visão não-retórica da realidade, atitude positiva e espírito empreendedor. Manzini (2008) complementa, dizendo que todas estão enraizadas em lugares específicos, fazem bom uso dos recursos locais e promovem maneiras diferentes de troca social, direta ou indiretamente. São também fortemente dependentes das relações que estabelecem com seus pares e com seu meio exterior. Dentro dessas comunidades surgem propostas inovadoras de ação coletiva que visam solucionar os problemas complexos encontrados na sociedade. $O$ aspecto coletivo é importante uma vez que dificilmente uma única pessoa terá todo conhecimento requerido para lidar com esses desafios, então a sabedoria relevante necessária para criar soluções estará, muitas vezes, distribuída entre os atores locais (ARIAS et al, 2000 apud FISCHER, GIACCARDI, 2004, p.15). Tais ações são entendidas como "casos promissores", ou seja, propostas
- de negócios ou serviços - que têm potencial de solucionar problemas de forma inovadora. Quando, e se, essas propostas evoluem e as comunidades amadurecem, elas se tornam empreendimentos sociais difusos, que são grupos de pessoas que se auto-organizam para obter os resultados que os interessam diretamente. Esses empreendimentos, ao ajudarem a si mesmos e (quase sempre) por si mesmos, estão automaticWupo e a malha social onde se inserem, melhorando a qualidade do ambiente. Já os casos promissores gerados por eles podem se converter em novas formas de serviços colaborativos; redes de cidadãos colaborativos; instituições participativas; e organizações colaborativas (MANZINI, 2008; JÉGOU, MANZINI, 2008).

Segundo Jégou e Manzini (2008), organizações colaborativas são iniciativas de serviços e produção empresariais que aprimoram as atividades de suas localidades ao encorajarem relações diretas entre produtores e consumidores que, neste caso, viram co-produtores das soluções projetadas. As relações íntimas pessoa-a-pessoa que são formadas, fazem com que exista a dependência na confiança mútua que se estabelece nas organizações, bem como criam os valores que serão compartilhados por toda comunidade.

As organizações colaborativas tendem a aparecer em contextos de mudanças profundas que trazem distúrbios urgentes. Por não se conformarem com o status quo do macro-sistema, elas propõem soluções que o desafiam e rompem, em escala local. Porém, para se estabelecerem de fato, as organizações colaborativas precisam que nesse contexto existam o que Florida (2011) chama dos 3Ts do desenvolvimento da economia criativa: tolerância (condições sociais e políticas); talento (ideias e habilidades distintas); e tecnologia (possibilidade de usar os recursos disponíveis de modo a dar vida às soluções). Uma vez presentes esses requisitos, observamos que passa a emergir um cenário diferenciado, descrito pela sigla SLOC (do inglês Small, Local, Open e Connected). Essas palavras qualificam um macro-sistema distribuído de produção e consumo, composto por uma rede integrada de diversas iniciativas locais. Pequeno indica a proporção que faz com que essas iniciativas e seus casos promissores sejam compreensíveis e controláveis pelos indivíduos e comunidades presentes em cada 
localidade (MANZINI, 2010). As trocas que ocorrem - entre as comunidades em rede e delas com esse macro-sistema - começam a delinear o raciocínio interligando organizações colaborativas com sistemas abertos.

Organizações colaborativas como sistemas abertos. Manzini (2008, p.31) vai dizer que "o sistema deve ser altamente integrado com seu contexto a fim de ser definido como sustentável", e diversas vezes vai caracterizar as organizações colaborativas com significados próximos aos de sistemas, embora não tenha proposto diretamente essa comparação. Queremos oferecer uma nova visão para o conceito de organizações colaborativas, explicitando seu lado sistêmico, pois, de fato, elas podem ser descritas segundo as definições de sistemas abertos: elas são entidades complexas cujo todo tem mais significado que o somatório de suas partes constituintes; não fazem sentido se isoladas do seu contexto; realizam trocas dinâmicas com o meio onde estão inseridas e delas dependem para manter o equilíbrio interior. A organização colaborativa, assim como o sistema aberto, é tão dependente do seu contexto que podemos dizer que ela não está no meio ambiente, de certa forma ela é o meio ambiente onde se encontra, influenciando-o na mesma medida que por ele é influenciada.

As organizações colaborativas se comportam de acordo com os quatro princípios dos sistemas abertos apresentados anteriormente, lidando com a imprevisibilidade dos contextos; evoluindo pelas mãos de seus usuários; podendo ser projetadas para a evolução distribuída no tempo, espaço e entre os indivíduos do sistema. A complexidade está presente tanto na composição dessa organização-sistema, feita de muitas camadas, elementos e estruturas; quanto nas relações que se estabelecem inter e intrassistema, e dele com seu meio ambiente.

Fazendo outro paralelo, vemos que o design estratégico também tem características de sistema aberto: ele organiza seu fechamento pela abertura, interagindo constantemente com o meio e realizando trocas informacionais e materiais, a fim de se adaptar ao ambiente; sua transdisciplinaridade faz com que os diversos atores envolvidos em suas ações ajam como co-criadores; e ele deve, preferencialmente, encontrar-se difundido em toda organização (sistema). Tendo tanto em comum, cabe perguntarmos de que forma o designer estratégico pode dar apoio às organizações colaborativas, entendidas como sistemas abertos? Como pode contribuir para o estabelecimento ou para a manutenção delas? E finalmente, como pode auxiliá-las, de modo que sejam replicáveis? Tentaremos apontar soluções para essas questões trazendo a contribuição do metadesign.

\section{METAPROJETO}

Metaprojeto é um framework conceitual que define e cria infraestruturas sociais e técnicas que evoluem com o tempo e o uso, nas quais novas formas de design colaborativo podem acontecer (FISCHER e GIACCARDI, 2004). Segundo os autores, o metadesign pode ser visto como o conhecimento sociotécnico com capacidade de endereçar três necessidades dos sistemas: de ter flexibilidade para evoluir com o tempo; de evoluir pela mão dos usuários; e de ser projetado para a evolução desde o princípio. Dessa forma, quando falamos em metaprojeto no contexto das organizações colaborativas, dois temas se sobressaem: a capacidade dessa abordagem em dar voz e ferramenta para os diversos atores agirem como co-designers; e a perspectiva de projetar a organização para ser um sistema aberto desde a sua concepção.

Projetando o sistema. Organizações colaborativas estão inseridas no âmbito da complexidade, tanto em relação à sua natureza, quanto referente ao ambiente onde se limitam e aos problemas que enfrentam. Tais problemas são entendidos como complexos pois, quase sempre, são mal definidos e, assim o sendo, não podem ser totalmente antecipados na hora em que o sistema é planejado, ou seja, na hora que a organização é projetada ou implementada (GIACCARDI, 2003). Como vimos, uma organização é um sistema aberto, então, naturalmente, não poderia ser concebida como um sistema fechado. Mesmo assim, é possível idealizar, desde o momento "zero", um sistema que seja não somente (e naturalmente) aberto, mas que tenha também as características necessárias para estimular sua evolução.

Projetar um sistema aberto evolutivo não significa fazer um projeto inacabado, mas sim um diferente, ao qual o L3D Centre, citado por Giaccardi (2003), chama de semente (seeding). A autora explica que a semente é projetada para ser expandida, para evoluir e fomentar o design colaborativo durante seu tempo de uso. Trata-se de um processo de adaptação contínua. Primeiro, a organização é planejada para se situar em um contexto específico, na forma de uma semente - um embrião de empreendimento que, quando lançado, responde às alterações do meio. Os atores internos do sistema, ao fazerem uso de suas facilidades, detectam falhas e problemas emergentes. De forma participativa, esses mesmos usuários 
co-criam as soluções para fazer com que o sistema evolua e se adapte às novas necessidades. Esse movimento contínuo de aprendizado coletivo está intrinsecamente ligado a outra propriedade do metaprojeto, primordial para a constituição de uma organização colaborativa, a qual veremos no próximo tópico (agir como um designer). Assim sendo, os meta-designers do sistema são considerados designers que projetam ambientes de design que podem ser modificados pelos co-designers na hora de seu uso.

Segundo Fischer e Giaccardi (2005), na medida em que as organizações evoluem, também o fazem seus atores, em um processo de definição e solução de um problema. Para dar suporte a essa co-evolução, o sistema deve incluir um método de adaptação conjunta entre usuários e sistema, por meio do qual os usuários se modificam ao interagirem com o sistema, bem como o sistema se adapta com as ações dos usuários. É importante ressaltar que, para os autores, a semente que gera o sistema não é nem um template e nem um esquema, mas antes disso é um pedaço de conhecimento, conteúdo ou código.

Queremos salientar a importância da semente na geração do sistema pois entendemos que existe aqui um grande potencial de replicar as organizações colaborativas em diferentes contextos. Sim, os sistemas são projetados de acordo com o contexto no qual estarão inseridos, e localidades diferentes têm contextos igualmente diferentes. Porém, como Manzini propõe:

Quando discutimos a possibilidade de difusão das organizações colaborativas, devemos levar em consideração que, na realidade, o que está sendo replicado não é esses casos altamente localizados com todas suas características, nem as comunidades criativas que os geraram, visto que são compostas obviamente por grupos de pessoas não replicáveis, mas sim as ideias de serviço que esses grupos de pessoas inventaram (MANZINI, 2008, p.89-90, grifo nosso).

O que pode ser replicado na semente é a ideia de serviço inventado ou adaptado, uma vez que os problemas sociais são semelhantes e se repetem em diversas partes do mundo. Bastaria que o contexto contivesse as premissas apresentadas (tolerância, talento e tecnologia), necessárias para fomentar o estabelecimento da semente e sua evolução. A possibilidade de projetar a priori a existência da organização, seguindo os critérios da colaboração e da co-criação, facilita sua evolução e sua constante adaptação ao meio.

Agir como designer. Podemos assumir que gran- de parte da humanidade tem as qualidades básicas de um designer, a saber: a vontade de criar, a curiosidade e o raciocínio inquisitivo. Porém somente algumas pessoas querem desenvolvê-las a ponto de se tornarem especialistas em design. Agora chegamos no momento em que é preciso instigar a criatividade e a participação de forma difusa, fazendo com que os mais diversos atores se tornem co-designers de inovações sociais. Fischer e Giaccardi (2004) explicam que o metaprojeto estabelece as condições para engajar os indivíduos, da participação no planejamento à participação na mudança contínua, dando a todas pessoas acesso ao banco de ferramentas e recursos que até então pertencia somente aos designers profissionais. Manzini (2003) propõe um novo papel para o designer, de facilitador no processo de aprendizado do design difuso, se afastando cada vez mais da figura tradicional do designer, para se tornar um ator que viabiliza o acontecimento de eventos e instiga a participação criativa das demais pessoas envolvidas na ação. Vamos assumir essa proposição positiva para o designer, enxergando-o como um especialista capaz de reger processos complexos com interações múltiplas, um meta-designer.

Fisher e Giaccardi (2004) chamam de informed participation (participação informada) a forma de design colaborativo em que indivíduos com diferentes conhecimentos transcendem além da informação dada para se converterem em donos dos problemas e, assim, contribuírem ativamente na construção das soluções. É exatamente isso que fazem as pessoas pertencentes às comunidades criativas, de acordo com Meroni (2007): elas são proativas e colaboram umas com as outras para inventar e gerenciar soluções para um modo diferente de viver. A ideia aqui é dar aos indivíduos a oportunidade e os recursos para promover o debate e o co-design, e não simplesmente entregar uma informação pronta e engessada com a qual pouco podem fazer.

Para poderem agir colaborativamente, os indivíduos precisam ter liberdade de expressão e de engajamento em atividades pessoalmente significativas, estando incorporados e ativos no sistema (FISCHER, GIACCARDI, 2005). Já vimos que as organizações colaborativas promovem relações entre produtores e consumidores, tornando esses últimos co-produtores de soluções. Mas de que forma o sistema consegue habilitar a participação ativa e criativa de todos indivíduos, tornando-os co-designers tanto de soluções quanto do próprio sistema? Apontamos algumas possibilidades: 
1. Usando o know how do designer especialista para difundir uma visão e propósito compartilháveis com todos atores do sistema, instigando-os a agir - usando as capacidades do designer "particularmente funcionais para a ação estratégica" que Zurlo (2010) definiu, a saber: a capacidade de ver (leitura orientada dos contextos e dos sistemas); de prever (antecipação crítica do futuro); e de fazer ver (comunicar cenários futuros);

2. A abertura do sistema ao meio obriga a rearticulação interna para manter seu equilíbrio. Essa adaptação constante deve ser regulada pelos atores internos, que precisam formular respostas aos problemas emergentes - senão, o sistema colapsa. A visão compartilhada e a difusão da cultura da organização aumentam o comprometimento para solucionar os problemas;

3. O sistema deve deixar que seus usuários se expressem, compartilhando emoções e experiências, de forma que se alternem no papel de "professores", "designers" e "aprendizes". Assim, passa a existir um repositório de conhecimento tácito tornado explícito, que pode ser acessado por todos, auxiliando o aprendizado geral. Esse tipo de compartilhamento de informação pressupõe que todos indivíduos têm contribuições ativas a fazer, dentro de suas capacidades ou especialidades. A chave está em fomentar a troca e o debate.

Como bem apontam Fischer e Giaccardi (2004), o metaprojeto é uma abordagem para superar os limites dos sistemas fechados, dando apoio para a participação informada e a criatividade social. Cabe ressaltar que, aqui, o metadesign não cria o conteúdo, mas sim o contexto, estando mais próximo de ser um modo do que um modelo, de design (VASSÃO, 2008) - atuando permanentemente, da concepção à manutenção do sistema, em um nível diferente daquele dos processos e da execução.

\section{CONSIDERAÇÕES FINAIS}

Os problemas socioambientais que enfrentamos têm tamanha complexidade que é impossível pensar em uma solução única e derradeira, que nos transporte de imediato a uma realidade equilibrada e sustentável. Acreditamos, assim como Ezio Manzini, que a transição para um novo macro-sistema socioambiental acontecerá de forma gradual, pautada por inúmeras iniciativas inovadoras, como as organizações colaborativas. A atuação dessas organizações ocorre, geralmente, em um movimento de baixo para cima na esfera social, pois a condição sine qua non de sua existência é a participação ativa dos atores di- retamente envolvidos no problema ou na sua solução. Embora apareçam com maior frequência neste nível de base da sociedade, as organizações colaborativas muitas vezes dependem de interações de cima para baixo ou de igual para igual para dar apoio às suas ações (JÉGOU, MANZINI, 2008). O conceito que propomos aqui para organizações colaborativas como sistemas abertos busca ampliar a compreensão dos mecanismos de atuação desses empreendimentos, de forma que se solidifiquem em suas localidades e consigam dar suporte de igual para igual a outras organizações, conectadas globalmente, que tentam sanar problemas semelhantes aos seus.

Ao estabelecermos o paralelo entre organizações colaborativas e sistemas abertos, trazemos à tona as contribuições metodológicas do metaprojeto para o estabelecimento, para a manutenção e até, possivelmente, para a replicação dessas entidades. Por terem características de sistemas abertos, como vimos, essas organizações podem ser concebidas desde o princípio para evoluir com o tempo e o uso e por intermédio dos seus usuários, através do seeding. A semente nada mais é que o projeto de um sistema evolutivo. $\mathrm{O}$ escopo desse projeto pode conter apenas informações básicas como, por exemplo, o conhecimento sobre como confrontar determinado problema comum a diversas localidades, e um mecanismo que possibilite o crescimento e a adaptação do sistema aos seus contextos do uso e do ambiente externo. Uma vez que uma organização já tenha se estabelecido e esteja desenvolvendo suas atividades com êxito, ela poderia disponibilizar abertamente o seu conhecimento-chave - aquele usado para solucionar o desafio que a trouxe à existência - de modo que pudesse ser usado como elemento central de uma semente replicável. Esse é, todavia, um raciocínio inicial, que necessita de aprofundamento em estudos futuros que possam testar sua aplicabilidade em situações reais.

O metaprojeto também contribui na concepção de um espaço de co-criação. É praticamente impossível projetar um sistema aberto evolutivo sem levar a premissa da colaboração em consideração, desde a concepção inicial do sistema até todas suas etapas de desenvolvimento, uma vez que a transformação da semente em uma organização depende da atuação conjunta dos diversos stakeholders. Os processos de co-design do sistema podem ser fomentados por, pelo menos, três ações: (1) a construção de um repositório de conhecimento tácito dos atores que se intercalam em diferentes papeis, tornando-o explícito; (2) o uso das habilidades do meta-designer (designer-facilitador), como, por exemplo, de 
gerar e difundir propósitos compartilháveis por todos; e (3) o incremento do comprometimento dos atores em resolver os problemas emergentes.

Nessa visão sistêmica das organizações colaborativas, o designer assume um novo papel como projetista do sistema aberto, se convertendo em um meta-designer, capaz de articular a evolução do sistema e facilitar a interação dos diversos atores co-designers. Entendemos que o designer não precisa temer essa nova atribuição, como se estivesse abrindo mão do seu conhecimento a caro custo aprendido, pois o que está acontecendo é apenas uma mudança, um deslocamento: de uma posição isolada e pouco compreendida (o criativo do departamento de design), o designer passa a exercer uma liderança significativa. Um papel através do qual poderá influenciar, criar e gerenciar as mudanças positivas do mundo. Reforçamos essa proposta com a provocação de Manzini (2008, p.98): "uma nova atitude de design está emergindo, convidando os designers a exercerem um fascinante papel. Aceitá-lo significa reconhecer positivamente que não é mais possível manter um monopólio de design".

Para concluir, convidamos todas pessoas a se tornem co-designers de uma nova realidade rumo ao bem-estar e à sustentabilidade.

\section{REFERÊNCIAS}

1. BEZERRA, M.C., PONTES, L.H. Organizações Sustentáveis: Você pode construí-las. Disponível em <https://organizacoessustentaveis.files.wordpress.com/2012/07/blog-6-de-julho.pdf $>$. Acesso em 20/08/2015.

2. BRAGA, Benedito, et al. Introdução à Engenharia Ambiental. São Paulo: Prentice Hall, 2002.

3. FISCHER, Gerhard, GIACCARDI, Elisa. Meta-Design: A Framework for the Future of End-User Development. In Lieberman, H., Paternò, F., Wulf, V. (Eds). End User Development: Empowering People to Flexibly Employ Advanced Information and Communication Technology. Dordrecht: Kluwer Academic Publishers, 2004.

4. FISCHER, Gerhard, GIACCARDI, Elisa. Creativity and Evolution: A Metadesign Perspective. 2005.

5. FLORIDA, Richard. A ascensão da classe criativa. Porto Alegre: L\&PM Editores, 2011.
6. FRANZATO, C. et al. Inovação cultural e social: design estratégico e ecossistemas criativos. In: FREIRE, K. (org.). Design estratégico para a inovação cultural e social. São Paulo: Kazuá, 2015, p. 157-182.

7. GIACCARDI, Elisa. Principles of Metadesign: Processes and Levels of Co-Cretion in the New Design Space. 2003. $437 \mathrm{f}$. Tese (Doctor of Philosophy) - University of Plymouth, UK. 2003.

8. GUATTARI, Felix. As três ecologias. 21a Edição. Campinas: Papirus Editora, 2012.

9. IPCC, 2014. Climate Change 2014: Synthesis Report. Contribution of Working Groups I, II and III to the Fifth Assessment Report of the Intergovernmental Panel on Climate Change [Core Writing Team, R.K. Pachauri and L.A. Meyer (eds.)]. IPCC, Geneva, Switzerland, 151 pp. DIsponível em <http://www.ipcc.ch/pdf/assessment-report/ar5/syr/SYR AR5_FINAL_full.pdf >. Acesso em 20/08/2015.

10. JÉGOU, François, MANZINI, Ezio. Collaborative Services: Social Innovation and Design for Sustainability. Milan: Edizioni Polidesign, 2008.

11. MANZINI, Ezio. Design para inovação social e sustentabilidade: Comunidades criativas, organizações colaborativas e novas redes projetuais. Rio de Janeiro: E-papers, 2008.

12. MANZINI, Ezio. Design Research for Sustainable Social Innovation. In: Design Research Now: Essays and selected projects. Germany: Birkhauser. 2007. Págs. 233-245.

13. MANZINI, Ezio. Small, Local, Open, and Connected: Design for Social Innovation and Sustainability. The Journal of Strategic Design: Change Design. Vol 4, № 1, 2010.

14. MANZINI, Ezio. Strategic Design for Sustainability: instruments for radically oriented innovation. In: JÉGOU, F. e

15.MANZINI, E. Sustainable Everyday: scenarios of urban life. Italy: Edizioni Ambiente, 2003.

16. MANZINI, Ezio e VEZZOLI, Carlo. O Desenvolvimento de Produtos Sustentáveis: Os requisitos ambientais dos produtos industriais. São Paulo: Edusp, 2011. 
17. MERONI, Anna (Ed). Creative Communities: People inventing sustainable ways of living. Milan: Edizioni Polidesign, 2007.

18. MORIN, Edgar. Introdução ao Pensamento Complexo. Porto Alegre: Editora Sulina, 2005.

19. THACKARA, John. Plano B: O design e as alternativas viáveis em um mundo complexo. São Paulo: Editora Saraiva, 2008.

20. VASSÃO, Caio A. Arquitetura Livre: Complexidade, Metadesign e Ciência Nômade. 2008. 319 f. Tese (Doutorado) Faculdade de Arquitetura e Urbanismo da Universidade de São Paulo, São Paulo. 2008.

21. ZURLO, Francesco. Design Strategico. In: XXI Secolo, vol IV, Gli spazi e le arti. Roma: Enciclopedia Treccani. 2010.

22.MANZINI, E.; JÉGOU, F. Scenarios for sustainable household. CIR.IS. Politecnico di Milano, p. 1-12, 1998.

23. MANZINI, E. JÉGOU, F. The construction of design-orienting scenarios. Final Report, SusHouse Project, Netherlands, Delft University of Technology, 2000.

24. MANZINI, E.; STASZOWISK, E. Introduction. public and collaborative. Exploring the intersection of design, social innovation and Public Policy. Desis Network, 2013.

25. MARGOLIN, V. The idea of design. Cambridge, MA: MIT Press, 1996.

26. MARGOLIN, V., MARGOLIN, S. Um modelo social de design: questões de prática e pesquisa. Revista Design in Foco, 2004.

27. MERONI, A. Strategic design: where are we now? Reflection around tha foundations of a recent discipline. Strategic Design Research Journal, v. 1, n. 1, p. 31-38 jul-dez.,2008.

28. MOUCHREK, N.; KRUCKEN, L. Laboratório de Design. Co-criação e sustentabilidade, uma iniciativa no ensino de design p. 1654-1666 . In: Anais do 11 Congresso Brasileiro de Pesquisa e Desenvolvimento em Design Blucher Design Proceedings, v. 1, n. 4. São Paulo: Blucher, 2014.
29. MURRAY, R. et al. The open book of social innovation. The Young Fundation, Innovating Public Services, 2010. REOS PARTNERS. Relatório Cenários Sociedade Civil 2023. São Paulo, 2013. Disponível na internet por http em < http://sociedadecivil2023.org.br/materiais/>. Acesso em 03/01/2014.

RUA, M.G. Análise de políticas públicas: conceitos básicos. 2001.

30. SOCIEDADE CIVIL 2023. 2013. Disponível na internet por http em < www.reospartners.com. > Acesso em 20/01/2014.

31. STASZOWSKI E. et al. Reflections on designing for social innovation in the public sector: a case study in New York City. Desis Network, 2013.

32. TEIXEIRA, E.C. O papel das políticas públicas no desenvolvimento local e na transformação da realidade, AATR-BA, 2002.

33. ZURLO, F. Design strategico. XXI Secolo. v. IV, Gli spazi e le arti. Roma: Enciclopedia Treccani. 2010. 